\title{
Ocorrência de insetos e uso de inseticidas naturais e sintéticos no armazenamento de sementes de nabo forrageiro ${ }^{1}$
}

\section{Occurrence of insects and use of natural and synthetic insecticides in the storage of seeds of wild radish}

\author{
Geraldo Cabral e Souza²; Juliana de Fátima Sales ${ }^{3}$; Fabiano Guimarães Silva; \\ Márcio Fernandes Peixoto ${ }^{3}$; Rafael Vieira Barbosa ${ }^{4}$
}

\section{Resumo}

Sabendo da importância do uso preventivo de inseticidas no tratamento de sementes, esta pesquisa teve por objetivos identificar possíveis insetos praga de armazenamento para sementes de nabo forrageiro por meio de armadilhas montadas em campo durante seis meses e avaliar o efeito de substâncias inseticidas, naturais e sintéticas na emergência de plântulas em sementes de nabo forrageiro armazenadas por 120 dias. O bioensaio, em nível de campo, foi conduzido por um período de seis meses nos seguintes ambientes: cerrado, área de cultivo de grandes culturas, pastagem e mata do Instituto Federal Goiano. Para cada um desses ambientes foram colocadas cinco armadilhas confeccionadas em garrafas PET, contendo respectivamente sementes de milho, milheto, soja, crambe e nabo forrageiro. As armadilhas foram inspecionadas a cada sete dias para a verificação da ocorrência de insetos praga. As substâncias consistiram de: 1) açafrão, 2) calcário, 3) cinza, 4) nim, 5) terra de diatomáceas, 6) clorpirifós, 7) deltametrina e 8) tratamento controle. O delineamento experimental foi em blocos ao acaso, no esquema fatorial 8 x 2, sendo oito substâncias e armazenamento por zero e 120 dias, com 4 repetições. Avaliaram-se porcentagem de emergência, índice de velocidade de emergência, tempo para atingir $50 \%$ da emergência e massa seca das plântulas emergidas. As substâncias naturais e sintéticas não interferem na emergência de plântulas em sementes de nabo forrageiro, mesmo após o armazenamento de 120 dias em sala climatizada. Nas armadilhas em campo contendo sementes de nabo forrageiro, foi observado a presença do inseto Carpophilus sp.

Palavras-chave: Armazenamento, emergência de plântulas, inseticidas

\begin{abstract}
Knowing the importance of preventive use of insecticides for seed treatment, this study aimed to identify potential insect pests of storage for seeds of radish by means of traps set on the field for six months and to evaluate the effect of natural and synthetic substances insecticides on the emergence of radish seedlings stored for 120 days. The bioassay, field-level, was conducted over a period of six months in the following environments: savannah, area of cultivation of crops, pasture and forest at the Federal Institute Goiano. For each of these environments were placed five traps made of PET bottles, containing respectively in maize, millet, soybean, crambe and wild radish. The traps were inspected every seven
\end{abstract}

\footnotetext{
${ }^{1}$ Pesquisa financiada pelo CNPq. Conselho Nacional de Desenvolvimento Científico e Tecnológico.

2 Prof. MSc. da Universidade de Rio Verde, FESURV e da Rede Municipal de Educação de Rio Verde, Goiás. Programa de PósGraduação em Ciências Agrárias, Instituto Federal Goiano, Campus, Rio Verde. Rio Verde, GO. E-mail: gcabralesouza@yahoo. com.br

${ }^{3}$ Profs. Drs. do Instituto Federal de Educação, Ciência e Tecnologia Goiano. Campus Rio Verde, GO. E-mail: juliana.sales@, pq.cnpq.br; fabianocefetrv@yahoo.com.br; marciofpeixoto@gmail.com

${ }^{4}$ Discente em Ciências Agrárias Instituo Federal Goiano, Campus Rio Verde, GO. E-mail: rafaelfera@gmail.com

* Autor para correspondência
} 
days to verify the the occurrence of insects plague. The substances were: 1) saffron, 2) limestone, 3) Gray, 4) neem, 5) diatomaceous earth, 6) chlorpyrifos, 7) deltamethrin and 8) control treatment. The experimental design was randomized blocks in factorial scheme $8 \times 2$ (8 substances and two storage periods, is not stored seeds and seeds stored for 120 days) with four replications. Were evaluated the percentage of emergence, hold rate of emergence, time to reach $50 \%$ emergence and the record of the dry mass of seedlings. The natural and synthetic substances do not interfere with seedling emergence in seeds of wild radish, even after storage for 120 days in a room. In the traps in the field, containing seeds of wild radish noted the presence of the insect Carpophilus $s p$.

Key words: Storage, seedling emergence, insecticides

O nabo forrageiro (Raphanus sativus L. var. oleiferus Metzg) apresenta elevado potencial de uso como matéria-prima para obtenção de biodiesel, uma vez que apresenta sementes com consideráveis teores de óleo de relativa facilidade de extração. Também possui elevado potencial produtivo no período de entressafras em épocas de pouca utilização ou pousio das terras agricultáveis (SILVA, et. al., 2007). É também de rápido crescimento e ciclo curto, o que a torna uma cobertura vantajosa em sistemas de rotação de culturas (AMADO; MIELNICZUK; VEZZANI, 2002).

Sabendo do interesse das empresas de sementes pelo produto, é necessário conhecer os aspectos fisiológicos das sementes dessa espécie, pois nem sempre são imediatamente processadas, havendo a necessidade de armazená-las até o ano seguinte para a sua semeadura. As condições de armazenamento e o tratamento fitossanitário definem a preservação da qualidade das sementes (CARVALHO; NAKAGAWA, 2000) e interfere na proteção contra pragas no campo.

Os carunchos e as traças provocam perdas de massa, desvalorização comercial, perda de valor nutritivo e diminuição de poder germinativo de sementes (GALLO et al., 2002). Ainda não há conhecimento de possíveis pragas de armazenamento para sementes de nabo forrageiro, provavelmente devido ao tegumento e a estrutura rígida das sementes. Outro fator a ser levado em consideração é o forte aroma exalado pelas sementes dessa espécie, característica marcante de óleos essenciais.
O controle de populações de pragas de grãos armazenados é feito, comumente, utilizando-se medidas de higienização, bem como aplicações preventivas com inseticidas organofosforados e piretróides, e curativas com o fumigante fosfina (BENHALIMA et al., 2004).

Um inseticida bastante utilizado é o deltametrina, que acrescido de butóxido de piperonila, se torna mais eficiente no combate de coleopteros, pois em sinergismo promovem o combate as enzimas oxidases multifuncionais (MFOs), que são responsáveis pela resistência nestes insetos à inseticidas (LORINI; GALLEY, 2000).

Devido aos riscos que os inseticidas químicos podem proporcionar ao homem, recentemente novas alternativas de controle de pragas de armazenamento vêm sendo estudadas, dentre as quais os inseticidas naturais. Entre os mais conhecidos se destaca o nim, usado primeiramente contra pragas caseiras e de armazéns, mas na Índia, seu país de origem, tem uso restrito às pragas da cultura do arroz (VIDIGAL et al., 2007). Dentre os mais de 40 terpenóides já identificados no nim, os mais típicos são os triterpenóides, dos quais a azadiractina, nimbina e salanina são os mais importantes, sendo encontrados em maior concentração nas sementes (MENEZES, 2005).

Além do nim, outras substâncias já foram testadas como inseticidas naturais, como as cinzas e o açafrão. Em sementes de feijão macassar, por exemplo, as cinzas são mais eficazes do que extratos de folhas de eucaliptos, no combate contra infestação de insetos (LIMA, et al., 1999). Em 
comparação com outros tratamentos químicos, a eficiência destes produtos naturais também é nítida, como observado por Previero et al. (2006), em sementes de milho tratadas com açafrão (Curuma longa $\mathrm{L}$ ) e armazenadas por até oito meses.

Millan et al. (2007) relatam também a eficiência de algumas substâncias naturais e sintéticas no combate à pragas de armazenamento. Armadilhas do tipo de caladores em silos de cevada tratados com os respectivos tratamentos (terra de diatomácea, deltametrina e fenitrotion) demonstram que a espécie C. ferrugineus foi predominante (71\%), enquanto que Sitophilus spp. e O. surinamensis representaram $17 \%$ e $11 \%$ dos insetos capturados.

Diante da escassez de informações sobre a sanidade das sementes de nabo forrageiro durante o armazenamento, este estudo teve como objetivos identificar possíveis pragas de armazenamento para sementes de nabo forrageiro e avaliar o efeito de substâncias naturais e sintéticas na emergência de plântulas em sementes de nabo forrageiro armazenadas por 120 dias.

Para a verificação de insetos-praga de armazenamento para sementes de nabo forrageiro, o bioensaio foi conduzido em nível de campo, a temperaturas e umidade relativa ambiente dos insetos nativos, por um período de seis meses nos seguintes ambientes: cerrado, área de cultivo de grandes culturas, pastagem e mata do Instituto Federal Goiano de Rio Verde.

Foram confeccionadas para cada um desses ambientes cinco armadilhas de garrafa PET de dois litros, com três furos de cinco centímetros de diâmetro na parte superior da garrafa, de coloração incolor. Em cada uma das armadilhas foi colocado $300 \mathrm{~g}$ de sementes, sendo nabo forrageiro, crambe, milho, milheto e soja respectivamente. As sementes de outras espécies comuns na região foram utilizadas para fins comparativos e também, no caso do crambe, que é uma oleaginosa da mesma família do nabo forrageiro.

As armadilhas foram fixadas no solo, a uma profundidade de cinco centímetros. Cada ambiente teve todas as sementes dispostas em armadilhas no mesmo ponto, garantindo a mesma chance de ataque de insetos nativos para todas as sementes.

As armadilhas e sementes foram inspecionadas em períodos de sete dias, iniciando-se no dia 26 de agosto de 2009 e encerrando no dia 3 de janeiro de 2010, verificando o ataque e/ou posturas dos insetos nativos. Para avaliar a eficácia dos tratamentos, periodicamente as sementes foram peneiradas e os insetos-pragas de interesse para o armazenamento quando presentes anotados. Foram considerados mortos os indivíduos que não reagiram ao toque de uma pinça. Os insetos vivos foram mantidos em frascos no laboratório de Entomologia da instituição. Com relação à oviposição, se houvesse, registrar-se-ia o número de ovos depositados sobre todos os grãos, assim como os ovos colocados nas paredes internas das armadilhas e frascos.

A identificação dos insetos foi efetuada com auxilio do manual de entomologia agrícola, classificando até o nível de gênero dos insetos.

$O$ efeito de substâncias naturais e sintéticas na qualidade fisiológica de sementes de nabo forrageiro foi estudado por meio de um experimento conduzido no Laboratório de Sementes do Instituto Federal de Educação, Ciência e Tecnologia Goiano - Campus Rio Verde.

As sementes de nabo forrageiro (Raphanus sativus L.) foram obtidas da empresa CATI, com a germinação mínima de $70 \%$, do cultivar CATIAL 1000, do lote: 1B-1.3.5/7, da safra de 2007/2007.

$\mathrm{O}$ delineamento experimental utilizado foi em blocos casualizados em esquema fatorial $8 \times 2$ ( 8 substâncias e 2 tempos de armazenamento), com 4 repetições, totalizando 64 unidades experimentais cada uma composta por 50 sementes. As substâncias, além do controle, consistiram de sementes tratadas com as seguintes substâncias: açafrão, nim, calcário, cinzas e terra de diatomácea, na forma de pó (6g) e, clorpirifós e deltametrina na forma de óleos $(0,15 \mathrm{ml})$. Todas as substâncias, inclusive os 
pós, foram diluídas em $5 \mathrm{ml}$ de água, para a melhor homogeneização das sementes. Inicialmente foi misturada $300 \mathrm{~g}$ de sementes de nabo forrageiro com os respectivos tratamentos, homogeneizando cada amostra por meio de agitação manual em saco plástico por dois minutos. Cada amostra foi subdividida em duas amostras, sendo a primeira semeada logo após o tratamento e a outra após 120 dias de armazenamento em sacos plásticos (de alta densidade para autoclave), em sala climatizada, sendo que a temperatura média do ar foi de $17,8^{\circ} \mathrm{C}$ e umidade relativa (UR) $60,3 \%$.

As sementes foram semeadas a 1,5 cm de profundidade em canteiros de emergência com nebulização intermitente. A temperatura média do ar na casa de vegetação foi de $23,4^{\circ} \mathrm{C}$ para a primeira semeadura e $25,23^{\circ} \mathrm{C}$ para sementes semeadas logo após os 120 dias de armazenamento, e a umidade relativa (UR) sendo respectivamente $75 \%$ e $84 \%$. As avaliações foram realizadas por meio de contagens diárias do número plântulas emergidas; a partir do $3^{\circ}$ dia de semeadura as contagens foram utilizadas para determinar o: IVE (índice de velocidade de emergência), estande (\% de emergência) e T50 (tempo médio para ocorrer $50 \%$ de germinação). Os cálculos de porcentagem e velocidade de emergência foram realizados de acordo com Maguirre (1962).

As plântulas obtidas no teste de emergência foram colocadas em sacos de papel e secas em estufa com circulação forçada de ar a $50^{\circ} \mathrm{C}$ até atingir massa constante. $\mathrm{O}$ material seco foi pesado em balança analítica com precisão de $0,001 \mathrm{~g}$, sendo resultado expresso em gramas por plântula.

Os dados dos experimentos foram analisados por meio de análise de variância usando o teste $\mathrm{F}$ até 5
$\%$ de probabilidade e as médias foram comparadas utilizando-se o teste de Scott-Knott, adotando-se o nível de 5\% de probabilidade. Tais análises foram realizadas com auxílio do programa estatístico Sisvar (FERREIRA, 2003).

No intervalo de seis meses de exposição das armadilhas no campo foram encontrados os gêneros: Lasioderma $s p$ no crambe; Triboluim $s p$ na soja, no milho e no crambe; Sitophilus $s p$ no milheto e Rhizopertha sp. no milho (Tabela 1). Em todo período de armazenamento não foram encontradas posturas nas armadilhas, sementes ou nos recipientes em que foram mantidos os adultos.

O gênero Carpophilus sp. foi encontrado em todos ambientes em que houve incidência de insetos e nas sementes de todas as espécies estudadas (Tabela 1), inclusive o nabo forrageiro. Essa espécie vive sobre grãos de cereais armazenados, sementes oleaginosas, cacau, nozes e diversas outras espécies de regiões tropicais e subtropicais, se tornando um problema em sementes com teor de água relativamente alto, um indicador de umidade e mofo no armazenamento.

A atratividade do inseto Carpophilus $s p$. pelas sementes de nabo forrageiro mostra evidências de problemas futuros no armazenamento de sementes dessa espécie no Brasil, quando houver o aumento da produção e extensão de áreas, principalmente nas culturas localizadas no bioma cerrado, uma vez que na mata auxiliar do IFGoiano/RV e no cerrado foi encontrado esse gênero. No Brasil há relatos da presença de Carpophilus sp. capturados em uma estrutura armazenadora de grãos, localizada na Fazenda Experimental Gralha Azul da Pontifícia Universidade Católica do Paraná, PR, coletadas no período de novembro de 2003 a maio de 2004 (PINTO JUNIOR; CERUTI; WEBER, 2005). 
Tabela 1. Datas, local, sementes e insetos encontrados nas armadilhas no período de 26/08/09 a 03/01/10.

\begin{tabular}{|c|c|c|c|}
\hline Datas $^{1}$ & Local $^{2}$ & Armadilha infestada ${ }^{3}$ & Praga encontrada \\
\hline \multirow[t]{3}{*}{$24 / 09 / 09$} & Mata IFG/RV & Soja & Tribolium $s p$. \\
\hline & & Milho & Tribolium sp. \\
\hline & & Crambe & Tribolium sp. \\
\hline $07 / 10 / 09$ & Cerrado & Crambe & Lasioderma sp. \\
\hline $17 / 10 / 09$ & Cerrado & Milheto & Carpophilus sp. \\
\hline $07 / 11 / 09$ & Mata IFG/RV & Crambe & Carpophilus sp. \\
\hline \multirow[t]{3}{*}{$14 / 11 / 09$} & Área (Grande Cultura) & Crambe & Carpophilus sp. \\
\hline & Mata IFG/RV & Crambe & Carpophilus sp. \\
\hline & & Milheto & Sitophilus sp. \\
\hline \multirow[t]{6}{*}{$03 / 01 / 10$} & Área (Grande Cultura) & Crambe & Carpophilus sp. \\
\hline & & Milho & Rhizopertha sp. \\
\hline & & Soja & Carpophilus sp. \\
\hline & Mata IFG/RV & Milheto & Carpophilus sp. \\
\hline & & Milho & Carpophilus sp. \\
\hline & & Nabo forrageiro & Carpophilus sp. \\
\hline
\end{tabular}

Datas referentes apenas às avaliações com insetos de interesse do trabalho.

Somente os locais onde ocorreram os insetos de interesse.

Somente as armadilhas que ocorreram à presença de insetos considerados pragas de sementes armazenadas.

Fonte: Elaboração dos autores.

Analisando a tabela 2, verificou-se que não houve nenhuma interferência das substâncias aplicadas nas sementes de nabo forrageiro para todas as características estudadas, mesmo após os 120 dias de armazenamento. Smiderle e Cicero (1999) também não observou efeito negativo de produtos naturais e sintéticos sobre o vigor das sementes de milho armazenadas por 12 meses, mesmo para os tratamentos em que foi aplicado terra de diatomácea ou clorpirifós usando o dobro da dose comercial ou deltametrina isolada ou associada com clorpirifós.

$\mathrm{O}$ aumento da porcentagem de emergência e a maior velocidade de emergência constatada no segundo tempo de armazenamento (120 dias) para as sementes de nabo forrageiro independente do tratamento aplicado leva a uma falsa impressão de aumento de vigor (Tabela 2). Porém, esse aumento pode ser resultado de uma dormência residual presente em algumas sementes, que segundo Marcos Filho (2005) não impede a germinação, mas torna o processo mais lento e desuniforme. Esse tipo de dormência apresenta profundidade inversamente proporcional à sua idade, ou seja, é mais intensa em sementes recém-colhidas. Dessa forma, a sua superação gradativa, acontece à medida que a semente envelhece.

De acordo com Marcos Filho (2005), a velocidade de germinação também é influenciada pela presença de carboidratos como os mananos que dificultam a protusão da raiz primária, em função da dificuldade para a digestão. Taxas respiratórias, mesmo que mínimas, e fatores que levam à deterioração das sementes durante o período de armazenamento contribuem para ausência ou decréscimo do teor desses polissacarídeos.

Analisando-se também a massa seca das plântulas, constatou-se que não houve diferença entre as sementes que receberam ou não as substâncias naturais e sintéticas independente do tempo de armazenamento. 


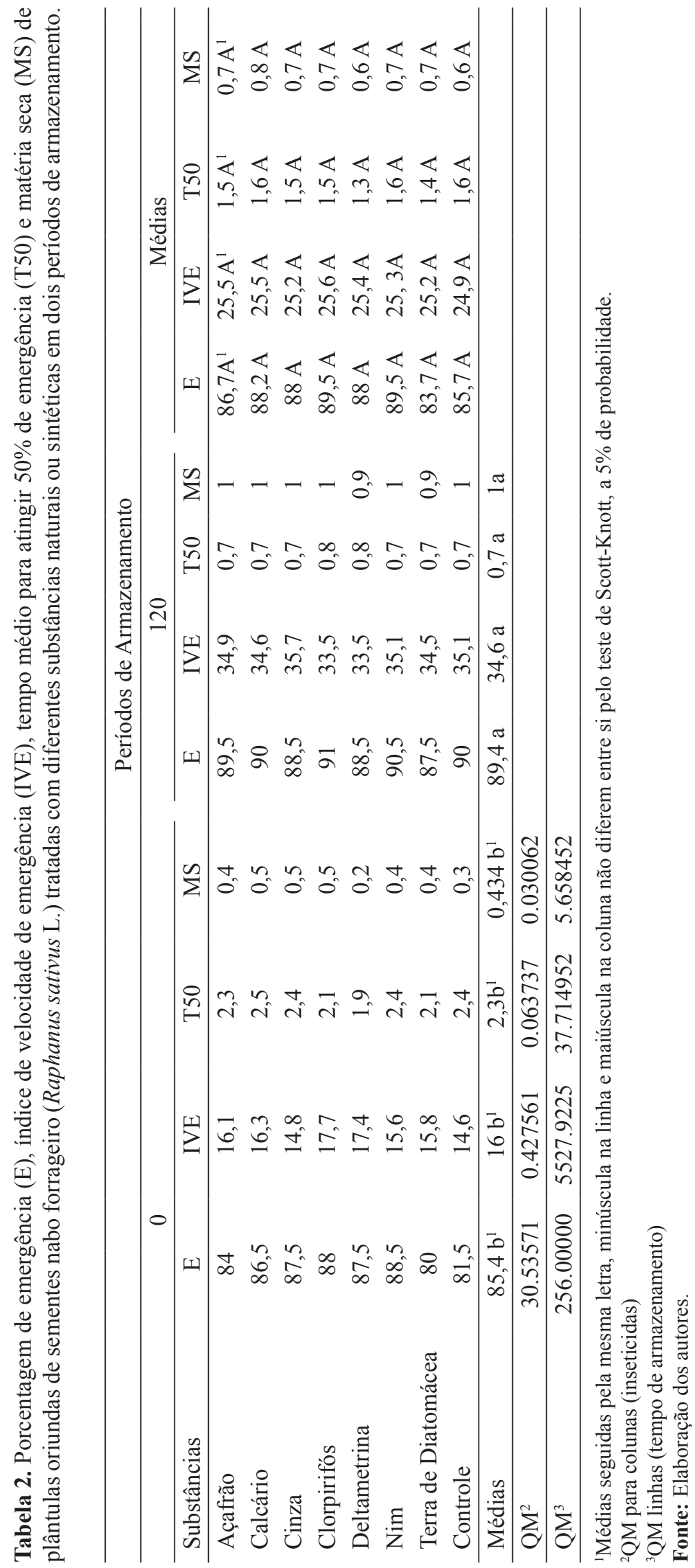


A elevação moderada da temperatura, como conseqüência do processo respiratório, já é suficiente para a decomposição dos lipídios o que favorece maior disponibilidade de energia para o embrião, o que pode explicar o aumento da matéria seca das plântulas em todos os tratamentos aos 120 dias de armazenamento.

Nas armadilhas em campo contendo sementes de nabo forrageiro, foi observado a presença do inseto Carpophilus sp. As substâncias naturais ou sintéticas não interferem na emergência de plântulas de sementes de nabo forrageiro (Raphanus sativus) durante o armazenamento das sementes tratadas.

\section{Referências}

AMADO, T. J. C.; MIELNICZUK, J.; VEZZANI, F. M. Nova recomendação de adubação nitrogenada para o milho sob plantio direto no RS e SC adaptada ao uso de culturas de cobertura do solo. Revista Plantio Direto, Passo Fundo, v. 2, p. 30-34, 2002.

BENHALIMA, H.; CHAUDHRY, M. Q.; MILLS, K. A.; PRICE, N. R. Phosphine resistance in stored-product insects collected from various grain storage facilities in Marocco. Journal of Stored Products Research, Oxford, v. 40, n. 3, p. 241-249, 2004.

CARVALHO, N. M.; NAKAGAWA, J. Sementes: ciência, tecnologia e produção. 4. ed. Jaboticabal: Funep, 2000.

FERREIRA, D. F. Sisvar: versão 4.2. Lavras: UFLA, 2003.

GALLO, D.; NAKANO, O.; NETO, S. S.; CARVALHO, R. P. L.; BATISTA, G. C.; FILHO, E. B.; PARRA, J. R. P.; ZUCCHI, R. A.; ALVES, S. B.; VENDRAMIM, J. D.; MARCHINI, L. C.; LOPES J. R. C.; OMOTO, C. Entomologia agrícola. Piracicaba: FEALQ, 2002.920 p.

LIMA, H. F.; BRUNO, R. de L. A.; BRUNO, G. B.; BANDEIRA, I. S. de A. Avaliação de produtos alternativos no controle de pragas e na qualidade fisiológica de sementes de feijão macassar armazenadas. Revista Brasileira de Engenharia Agrícola e Ambiental, Campina Grande, v. 3, n. 1, p. 49-53, 1999.

LORINI, I.; GALLEY, D. J. Effect of the synergists piperonyl butoxide and DEF in deltamethrin resistance on strains of Rhyzopertha dominica (F.) (Coleoptera: Bostrychidae). In: SOCIEDADE ENTOMOLÓGICA DO BRASIL, 29, 2000, Londrina. Anais... Londrina: [s.n.], 2000. p. 749-755.

MAGUIRRE, J. D. Speed of germination aid in selection and evaluation for seedling and vigour. Crop Science, Madison, v. 2, n. 2, p. 176-177, 1962.

MARCOS FILHO, J. Fisiologia de sementes de plantas cultivadas. Piracicaba: FEALQ, 2005, 495 p.

MENEZES, E. L. A. Inseticidas botânicos: seus princípios ativos, modo de ação e uso agrícola. Embrapa: Seropédica. 2005. (Documentos, 205).

MILLAN, M. M.; CRUZ, M. E. da S.; SOUZA, S. P. J.; FERREIRA G. da S. S.; FERREIRA, R. B. Efeito inseticida da terra diatomácea em cevada armazenada. Revista Brasileira de Agroecologia, Bahia, v. 2, n. 2, p. 1135-1139, 2007.

PINTO JUNIOR, A. R.; CERUTI, F.; WEBER, S. H. Monitoramento de insetos em estrutura armazenadora através de armadilha com atrativo alimentar localizada fora dos silos. Revista Acadêmia: Ciências Agrárias e Ambientais, Curitiba, v. 3, n. 1, p. 35-41, 2005.

PREVIERO, C. A. NOBREGA, S. L.; FERNANDEZ, G. A. V.; MARANHÃO, N. P.; SAMPAIO, C. P. Avaliação do falso-açafrão na qualidade de sementes de milho (Zea mays L.) armazenado. In: CONGRESSO BRASILEIRO DE ENGENHARIA AGRÍCOLA, 35; JORNADA DE INICIAÇÃO CIENTÍFICA DO CEULP/ULBRA, 9., 2006, João Pessoa. Anais... João Pessoa: ULBRA, 2006.

SILVA, A. R. B.; SILVA, T. R. B.; SILVA, M. L. L.; VIANNA, J. F.; MARTINEZ, M. M.; VIANAS, L. H.; SILVA, R. F. Comportamento de cultivares de nabo forrageiro (Raphanus sativus L.) em função da variação do espaçamento entre linhas. 2007. Disponível em: $<\mathrm{http} /$ www.portaldobiodiesel. gov.br $>$. Acesso em: 15 jan. 2007.

SMIDERLE, O. J., CICERO, S. M. Tratamento inseticida e qualidade de sementes de milho durante o armazenamento. Scientia Agricola, Piracicaba, v. 56, n. 4, p. 1245-1254, out./dez. 1999.

VIDIGAL, D. S.; BRASILEIRO, B. G.; DIAS, D. C. F. S.; ALVARENGA, E. M.; BHERING, M. C. Germinação e morfologia do desenvolvimento pós-seminal de sementes de nim-indiano (Azadirachta indica A. Juss.Meliaceae). Revista Brasileira de Sementes, Brasília, v. 29, n. 3, p. 39-46, 2007. 
